\title{
SEISMOGENIC NODES DEFINED BY PATTERN RECOGNITION IN THE CENTRAL PART OF THE ALPINE- HIMALAYAN BELT
}

\author{
Novikova O. ${ }^{1}$ and Gorshkov A. ${ }^{1,2}$ \\ ${ }^{1}$ Institute of Earthquake Prediction Theory and Mathematical Geophysics, Federal Agency for \\ Scientific Organizations, 84/32 Profsouznaya, Moscow 117997, Russia, onovikov@mitp.ru \\ ${ }^{2}$ Institut de Physique du Globe de Paris, Sorbonne Paris Cité, Univ. Paris Diderot, UMR 7154 \\ CNRS. 1 rue Jussieu, 75238 Paris, Cedex 05, France, gorshkov@mitp.ru, gorshkov@ipgp.fr
}

\begin{abstract}
Information on the areas prone to the strongest earthquakes in a region is very important for knowledgeable seismic hazard and risk assessment. We consider the central part of the Alpine-Himalayan Belt (Caucasus-Kopet Dagh-Alburz) for the recognition of seismogenic nodes capable of $M 7+$ earthquakes. The nodes formed around the intersections of the fault zones are viewed as objects of recognition which have been described by the common set of geologic, geomorphologic and geophysical parameters. 150 nodes out of 510 ones delineated in the Caucasus-Kopet DaghAlburz region were recognized prone for earthquakes $M 7+$. We have recognized a number of capable nodes where earthquakes $M 7+$ have not yet been recorded.

Keywords: seismic hazard, criteria of seismicity, earthquake.
\end{abstract}

\section{Introduction}

The study region embraces the central part of the Alpine-Himalayan belt presented by a system of young mountain systems and basins that reveal a high level of recent and past seismic activity (Ambraseys et al., 1982; Engdahl et al., 1998; Berberian, 1992; Kondorskaya et al., 1993; Shebalin et al., 1998). This region is an area of dense population and sensitive industrial infrastructure, for which the reliable seismic hazard assessment is a problem of a great practical importance. During last decades number of works dedicated to seismic hazard assessment at a local and regional scale have been conducted for this region using probabilistic approach (e.g. Balassanian et al., 1999; Shabani et al., 2007; Moinfar et al., 2012).

In this work, for identification of earthquake prone areas we employ the phenomenological approach based on the idea that large earthquakes correlate with morphostructural nodes forming around intersections of the fault zones (Gelfand et al., 1972; Gorshkov et al., 2003). The goal of this work is to identify seismogenic nodes prone to earthquakes M7+ in the region shown in Figure 1.

The methodology used has been systematically tested in many seismic regions of the world. Recent earthquakes occurred in the previously studied regions with the methodology employed in this work have proved the sufficient reliability of the methodology. Specifically, Soloviev et al. (2014) demonstrated that $87 \%$ of the post-publication events with target magnitudes occurred at the nodes recognized in advance as the seismogenic ones. 


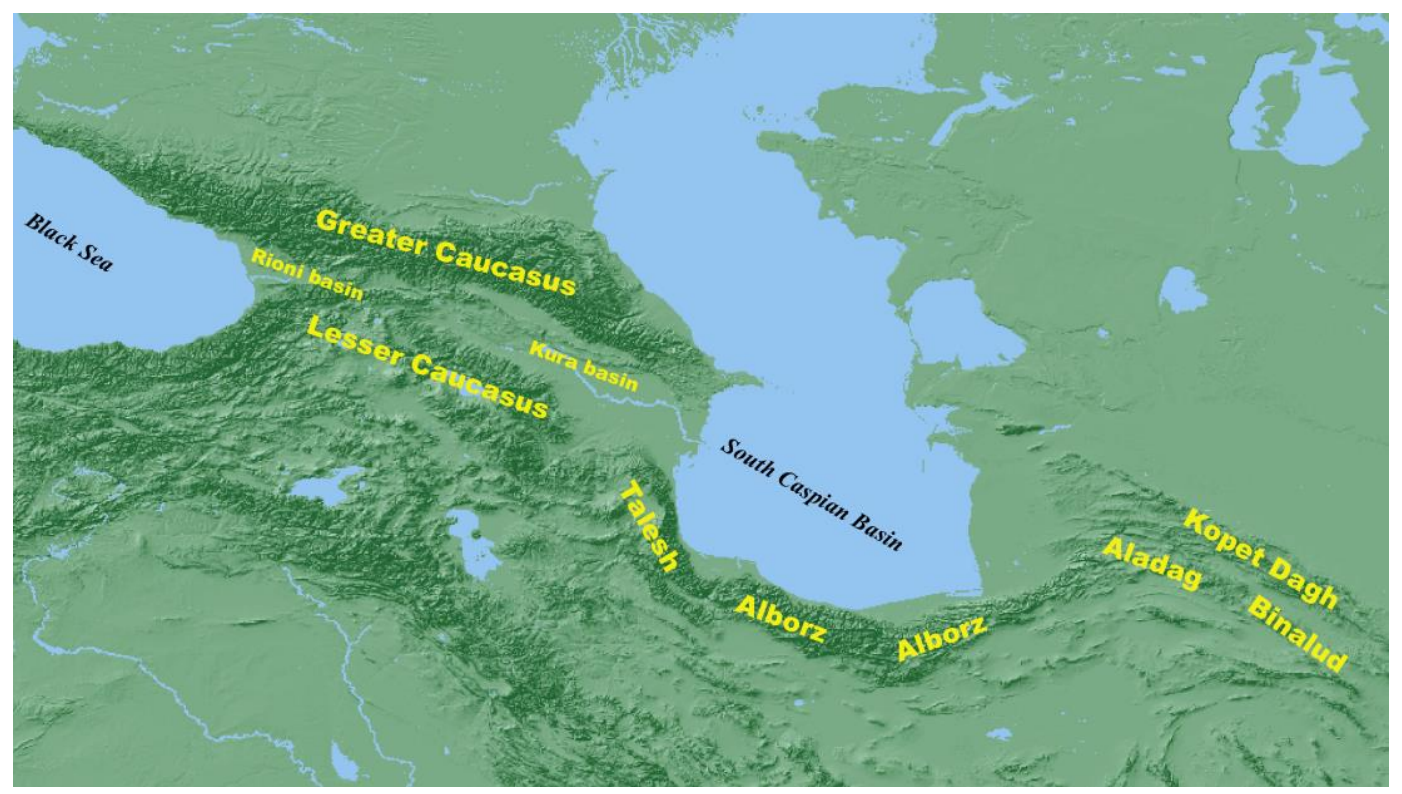

Figure 1 - Major structures of the study region.

\section{Methodology}

The methodology used combines a Morphostructural Zoning (MZ) method, which defines a set of nodes, and a pattern recognition technique which classifies the nodes by similarity of geomorphicgeological-geophysical features (Gelfand et al., 1972).

\subsection{Morphostructural Zoning Method}

The morphostructural zoning (MZ) map of the study region has been compiled using topographic maps, satellite images, geological and tectonic maps. MZ was performed deliberately ignoring seismicity data (earthquake catalogues). In the MZ (Gorshkov et al., 2003) the study region is divided into a system of hierarchically ordered areas of the homogeneous present-day topography and tectonic structure. MZ distinguishes (1) blocks (areas) of different rank; (2) their boundary zones, morphostructural lineaments; and (3) sites where lineaments intersect, the nodes. The rank of the lineament depends on the rank of the area limited by the lineament. With respect to the regional trend of the tectonic structure and topography, two types of lineaments are distinguished: (1) longitudinal and (2) transverse ones. Longitudinal lineaments are approximately parallel to the regional strike of the tectonic structure and of the topography and, as a rule, include the prominent faults. Transverse lineaments go across the regional trend of the tectonic structure and of the topography. Normally, they appear on the Earth's surface discontinuously and are evidenced by escarpments, by rectilinear parts of river valleys, and partly by faults.

\subsection{Recognition of Earthquake-Prone Areas}

The goal of the recognition is to separate the nodes into two classes: the nodes where earthquakes with magnitude $M \geq 7.0$ may occur (class $\mathbf{D}$ ) and the nodes where only earthquakes with $M<7.0$ may occur (class $\mathbf{N}$ ). Using the information on the recorded large earthquakes two sample sets of nodes are specified: $\mathbf{D}_{\mathbf{0}}$ representing class $\mathbf{D}$ and $\mathbf{N}_{\mathbf{0}}$ representing class $\mathbf{N}$. Each node is described by the topographical, geological, geomorphic, and geophysical parameters. The values of the parameters form a vector that is associated with a node. The vectors are classified into classes $\mathbf{D}$ and $\mathbf{N}$ using pattern recognition techniques, specifically the CORA-3 algorithm (Gorshkov et al., 2003) that operates in two stages. At the learning stage the algorithm selects the characteristic $\mathbf{D}$ - and $\mathbf{N}$ traits for classes $\mathbf{D}$ and $\mathbf{N}$, using samples $\mathbf{D}_{\mathbf{0}}$ and $\mathbf{N}_{\mathbf{0}}$. At the classification stage the algorithm counts 
the numbers of $\mathbf{D}$ - and $\mathbf{N}$-traits ( $n_{\mathrm{D}}$ and $n_{\mathrm{N}}$ respectively) that each node possesses and assigns it to class $\mathbf{D}$ if $n_{\mathrm{D}}-n_{\mathrm{N}} \geq \Delta$ or to class $\mathbf{N}$ if $n_{\mathrm{D}}-n_{\mathrm{N}}<\Delta$, where $\Delta$ is a parameter of the algorithm.

\section{Data and Results}

The MZ map displayed in Figure 2 shows morphostructural lineaments and loci of the nodes. Totally, with MZ we have identified 510 intersections of lineaments treated as the nodes. The node is defined as a circle of $30 \mathrm{~km}$ in the radius about the point where lineaments intersect. Such node dimension is consistent with the size of earthquake sources for M7+ (Wells and Coppersmith, 1994).

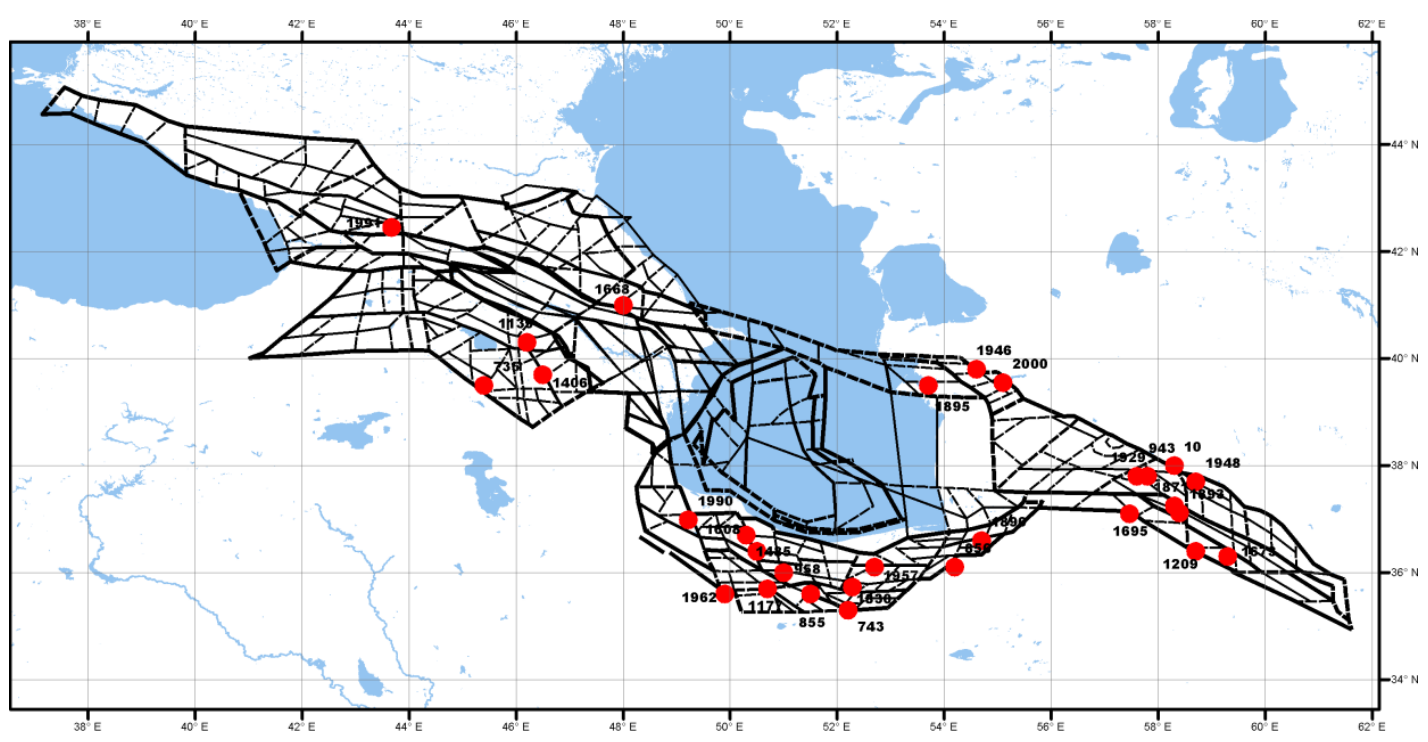

Figure 2 - Morphostructural zoning map of the central part of the Alpine-Himalayan belt.

Continuous lines - the longitudinal lineaments, dashed lines - the transverse lineaments; bold lines the lineaments of the $1^{\text {st }}$ rank, middle lines - the lineaments of the $2^{\text {nd }}$ rank, hairlines - the lineaments of the $3^{\text {rd }}$ rank.

All nodes have been described by the uniform set of parameters listed in the Table 1. Values of parameters are the input for the recognition algorithm Cora-3.

For the learning stage of the recognition the shallow earthquakes M7+ have been selected from the earthquake catalogs spanning different time intervals and covering totally or partially the study region (Engdahl et al., 1998; Berberian, 1994; Kondorskaya et al., 1993; Shebalin et al., 1997). All the epicenters plotted in Figure 2 correlate with the nodes.

The set $\mathbf{D}_{\mathbf{0}}$ of samples for the class $\mathbf{D}$ includes nodes where earthquakes with $M \geq 7.0$ already occurred. The set $\mathbf{N}_{\mathbf{0}}$ of samples for the class $\mathbf{N}$ contains the remaining nodes.

At the recognition stage the Cora-3 algorithm assigned 150 nodes out of 510 ones to class $\mathbf{D}$. Recognized seismogenic nodes capable of earthquakes with $\mathrm{M} \geq 7.0$ are shown in Figure 3.

Lines and red dots are the same as in Figure 2. Circles mark recognized nodes capable of earthquakes $\mathrm{M} 7+$.

Characteristic features defined by Cora- 3 that discriminate $\mathbf{D}$ nodes from $\mathbf{N}$ nodes are presented in Table 2. 
Table 1 - Parameters Used for the Recognition and Their Thresholds of Discretization.

\begin{tabular}{|c|c|c|c|}
\hline \multirow[t]{2}{*}{ Parameters } & \multicolumn{3}{|c|}{$\begin{array}{l}\text { Thresholds of discretization for the different parts of the } \\
\text { united region }\end{array}$} \\
\hline & Caucasus & Kopet Dagh & Alburz \\
\hline $\begin{array}{l}\text { Maximum altitude, } m \\
(\text { Hmax })\end{array}$ & 2642.01 & 1900 & 2544.01 \\
\hline $\begin{array}{l}\text { Minimum altitude, } \mathrm{m} \\
\text { (Hmin) }\end{array}$ & 290 & 340 & 100 \\
\hline $\begin{array}{l}\text { Relief contrast, m }(\Delta \mathrm{H}) \\
(\mathrm{Hmax}-\mathrm{Hmin})\end{array}$ & $1532 ; 2470$ & $1100 ; 1623$ & $728 ; 2370$ \\
\hline Measure of slope, $(\Delta \mathrm{H} / \mathrm{L})$ & 54.2 & 38 & 48.39 \\
\hline $\begin{array}{l}\text { The percentage of } \\
\text { Quaternary deposits, \% (Q) }\end{array}$ & $10 ; 48$ & 42,62 & $4 ; 49$ \\
\hline $\begin{array}{l}\text { The highest rank of a } \\
\text { lineament in the node, (HR) }\end{array}$ & 1 & 1 & 1 \\
\hline $\begin{array}{l}\text { The number of lineaments } \\
\text { in the node, (NL) }\end{array}$ & 2 & 2 & 2 \\
\hline $\begin{array}{l}\text { The distance from the node } \\
\text { to the nearest first rank } \\
\text { lineament, } \mathrm{km},(\mathrm{R} 1)\end{array}$ & 0,32 & 0,0 & 0,20 \\
\hline $\begin{array}{l}\text { The distance from the node } \\
\text { to the nearest second rank } \\
\text { lineament } \mathrm{km},(\mathrm{R} 2)\end{array}$ & 26 & 32 & 13 \\
\hline $\begin{array}{l}\text { The distance from the node } \\
\text { to the nearest intersection, } \\
\mathrm{km} \text {, (Rint) }\end{array}$ & 24 & 23 & 15 \\
\hline $\begin{array}{l}\text { Combinations of large } \\
\text { topographic forms (Top) } \\
1 \text { - mountain range and a } \\
\text { piedmont plain }(\mathrm{m} / \mathrm{p}) \\
\text { 2- mountain range and } \\
\text { piedmont hills }(\mathrm{m} / \mathrm{pd}) \\
\text { 3- mountain ranges } \\
\text { separated by a longitudinal } \\
\text { valley }(\mathrm{m} / \mathrm{m})\end{array}$ & & & \\
\hline $\begin{array}{l}\text { 4- piedmont hills and a } \\
\text { piedmont plain }(\mathrm{pd} / \mathrm{p})\end{array}$ & 3,4 & 1,2 & 2,4 \\
\hline
\end{tabular}


Table 2 - Characteristic Features of $D$ and N nodes.

\begin{tabular}{|c|c|c|c|c|c|c|c|c|c|}
\hline \multicolumn{10}{|c|}{ Parameters } \\
\hline $\begin{array}{c}\text { Hmax, } \\
\mathbf{M}\end{array}$ & $\begin{array}{c}\text { Hmin } \\
\text { m }\end{array}$ & $\begin{array}{c}\Delta \mathbf{H}, \\
\mathbf{m}\end{array}$ & TOP & $\begin{array}{l}\mathbf{Q}, \\
\%\end{array}$ & HR & NL & $\mathrm{dH} / \mathrm{L}$ & $\begin{array}{l}\text { R1, } \\
\text { km }\end{array}$ & $\begin{array}{l}\mathbf{R} 2, \\
\mathbf{K m}\end{array}$ \\
\hline \multicolumn{10}{|c|}{ D traits } \\
\hline & Large & Large & & & & & & & Large \\
\hline \multirow[t]{3}{*}{ Small } & & Large & & & & & & & \\
\hline & & & & Large & & & Large & & N/small \\
\hline & & Large & & & & Large & & & N/small \\
\hline Small & & N/small & & & & & & & N/small \\
\hline Large & & & & & & & & Large & Small \\
\hline \multirow[t]{3}{*}{ Large } & & & & $\mathrm{N} / \mathrm{small}$ & & & & & Small \\
\hline & & Large & & N/large & & & & Small & \\
\hline & Small & & & N/large & & & Large & & \\
\hline \multirow[t]{2}{*}{ Small } & & & & N/large & & & Large & & \\
\hline & & N/large & & $\mathrm{N} / \mathrm{small}$ & & & Large & & \\
\hline \multirow[t]{3}{*}{ Small } & Large & & & & & & Large & & \\
\hline & & N/small & Small & & & & Small & & \\
\hline & & Large & Large & & & Large & & & \\
\hline \multirow[t]{3}{*}{ Large } & & N/large & & & & Large & & & \\
\hline & & N/small & & $\mathrm{N} / \mathrm{small}$ & $\begin{array}{c}\mathrm{N} / \mathrm{smal} \\
1\end{array}$ & & & & \\
\hline & Large & Large & & Large & & & & & \\
\hline \multicolumn{10}{|c|}{$N$ traits } \\
\hline & & & & & & & & Large & Large \\
\hline & & & & & Large & & & & Large \\
\hline & & & & & & & Small & & N/large \\
\hline & & & & & & Small & Small & & Small \\
\hline & & Small & & & & Small & Small & & Small \\
\hline \multirow[t]{7}{*}{ Small } & & & & & & Small & Small & & Small \\
\hline & & Small & Large & & & Small & Small & & Small \\
\hline & Small & & & & & Small & Small & Large & \\
\hline & & & & & Small & & Small & & \\
\hline & Small & & Large & & Large & & & & \\
\hline & & Small & & & Large & & & & \\
\hline & Small & Small & & & Large & & & & \\
\hline
\end{tabular}




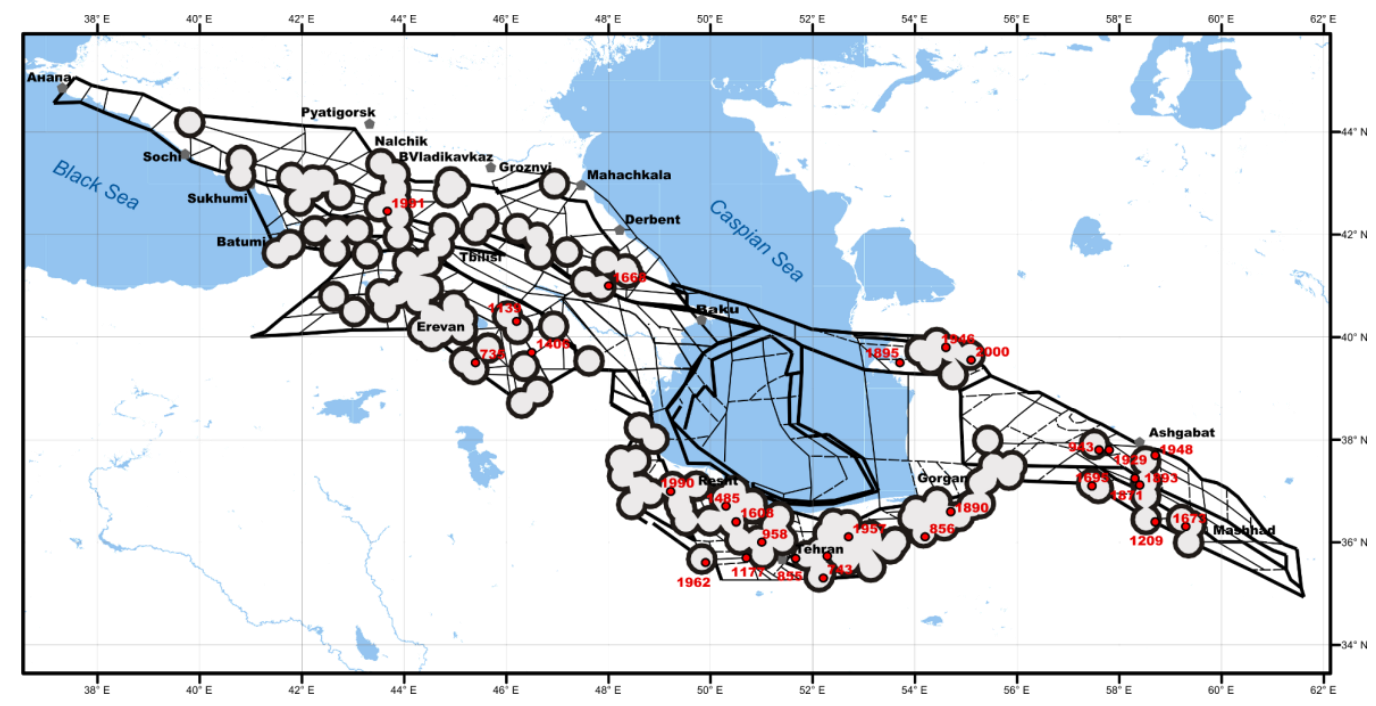

Figure 3 - Recognized Earthquake-Prone Areas for M7+.

\section{Discussion and Conclusions}

The obtained results are reasonable because we have recognized properly all the nodes hosting earthquake M7+ (Figure 3). We missed only one node accommodating the 1895 Krasnovodsk earthquake, the location of which is poorly defined (Balassanian et al., 1999).

Figure 3 shows that the majority of the recognized $\mathbf{D}$ nodes sit on the 1st and 2nd rank lineaments. This indicates that seismogenic nodes are located on the boundaries separating the largest blocks of the crust in the study region.

Note that within the South Caspian deep-sea basin characterized by the thin oceanic crust and a high heat flow nodes capable of earthquakes with M7+ are not recognized.

Characteristic features $\mathbf{D}$ and $\mathbf{N}$ nodes (Table 2) include 10 parameters that are most informative for the discrimination of $\mathbf{D}$ nodes from $\mathbf{N}$ ones. Unlike $\mathbf{N}$ nodes, $\mathbf{D}$ nodes are characterized by the contrast neotectonic movements and increased fragmentation of the crust. Specifically, "large" values of $\Delta \mathrm{H}, \mathrm{Q}$, and Hmax indicate the high contrast of neotectonic movements. In the vicinities of D nodes the increased fragmentation of the crust evident in "large" values of NL and in "small" values of R2.

Recognition results highlight the significant seismic potential of the central segment of the AlpineHimalayan belt: we recognized 126 D-nodes $\left(\mathbf{D}^{*}\right)$ where earthquakes M7+ have not yet been recorded. These nodes form the prominent clusters in each of the large-scale tectonic structures composing the central segment of the Alpine-Himalayan belt.

Most of $\mathrm{D}^{*}$ nodes are located in the Caucasus. Figure 3 shows that the largest cluster of $\mathrm{D}^{*}$ nodes is situated north of Erevan in the Armenian part of the Lesser Caucasus. In the Greater Caucasus D* nodes form several clusters occupying the southern flank of the Main Caucasus Range. The isolated D* nodes were recognized north of the Sochi and Sukhumi towns and, in the eastern part of the Greater Caucasus, near the towns of Nalchik, Vladikavkaz, and Makhachkala.

In the Alborz, large clusters of $\mathrm{D}^{*}$ nodes are located in the westernmost and easternmost parts of the mountain system. Another prominent area of high seismic potential is delineated near and east of Tehran.

In the Kopet Dagh we have recognized only a few D* nodes. They are concentrated in the southwest and in the northwest edges of the Kopet Dagh. 
Thus, the present study is considered to provide the important information on the potential earthquake sources for long-term seismic hazard assessment in the central part of the AlpineHimalayan belt.

\section{Acknowledgements}

The research has been partly supported by the RFBR (grants 15-55-45005, 16-55-12033 and 15-5554016).

\section{References}

Ambraseys, N.N. and Melville, C.P., 1982. A History of Persian Earthquakes, Cambridge University Press, Cambridge, MA, 219 pp.

Balassanian, S., Ashirov, T. and Chelidze, T., 1999. Seismic hazard assessment for the Caucasus test area, Annali di Geofisica, 42(6), 1139-1151.

Berberian, M., 1994. Natural hazard and the first earthquake catalogue of Iran, Volume1, Historical hazards in Iran Prior to 1900, IIEES, Thehran, 605 pp.

Engdahl, E.R., Van Der Hilst, R. and Buland, R., 1998. Global teleseismic earthquake relocation with improved travel times and procedures for depth determination, Bull. Seism. Soc. Am., $88,722-743$.

Gelfand, I.M., Guberman, Sh.A., Izvekova, M., Keilis-Borok, V.I. and Rantsman, E.Ya., 1972. Criteria of high seismicity determined by pattern recognition, Tectonophysics, 13(1-4), 415422.

Gorshkov, A., Kossobokov, V. and Soloviev, A., 2003. Recognition of Earthquake-Prone Areas. In: Keilis-Borok, V.I. and Soloviev, A.A., eds., Nonlinear Dynamics of the Lithosphere and Earthquake Prediction, 239-310, Springer-Verlag, Berlin-Heidelberg, 337 pp.

Kondorskaya, N., Gorbunova, I., Kireev, I. and Vandysheva, N., 1993. On the unified earthquake catalog of North Euroasia. In: Ulomov, V., eds., Seismisity and seismic zoning of North Eurasia, 70-79, IPE, Moscow, 300 pp.

Moinfar, A.A., Naderzadeh, A. and Nabavi, M.H., 2012. New Iranian Seismic Hazard Zoning Map for New Edition of Seismic Code and Its Comparison with Neighbor Countries, Proc. of the 15 WCEE conference, Lisbon, Portugal, 10-15 June, 122-132.

Shabani, E. and Mirzaei, N., 2007. Probabilistic seismic hazard assessment of the KermanshahSanandaj region of western Iran, Earthquake Spectra, 23(1), 175-197.

Shebalin, N.V. and Tatevosian, R.E., 1997. Catalogue of large historical earthquakes of the Caucasus. In: Giordini, D. and Balassanian, S., eds., Historical and prehistorical earthquakes in the Caucasus, 201-232, NATO ASI Series, 2. Enviroment, Vol.28. Kluwer Academic Publishers: Dordrecht/Boston/London. 359 pp.

Soloviev, A.A., Gvishiani, A.D., Gorshkov, A.I., Dobrovolsky, M.N. and Novikova, O.V., 2014. Recognition of Earthquake-Prone Areas: Methodology and Analysis of the Results: Izvestiya, Physics of the Solid Earth, 50(2), 151-168, doi: 10.1134/S1069351314020116.

Wells, D.L. and Coppersmith, K.J., 1994. New empirical relationships among magnitude, rupture length, rupture width, and surface displacement, Bull. Seism. Soc. Am., 84, 974-1002. 